\title{
Multivariate return periods of sea storms for coastal erosion risk assessment
}

\author{
S. Corbella ${ }^{1,2}$ and D. D. Stretch ${ }^{1}$ \\ ${ }^{1}$ Centre for Research in Environmental, Coastal \& Hydrological Engineering, Civil Engineering Program, \\ University of KwaZulu-Natal, Durban, 4041, South Africa \\ ${ }^{2}$ eThekwini Municipality, Coastal Engineering \& Drainage Unit, P.O. Box 680, Durban, 4001, South Africa
}

Correspondence to: S. Corbella (corbellas@ durban.gov.za)

Received: 11 April 2012 - Revised: 24 July 2012 - Accepted: 2 August 2012 - Published: 24 August 2012

\begin{abstract}
The erosion of a beach depends on various storm characteristics. Ideally, the risk associated with a storm would be described by a single multivariate return period that is also representative of the erosion risk, i.e. a $100 \mathrm{yr}$ multivariate storm return period would cause a $100 \mathrm{yr}$ erosion return period. Unfortunately, a specific probability level may be associated with numerous combinations of storm characteristics. These combinations, despite having the same multivariate probability, may cause very different erosion outcomes. This paper explores this ambiguity problem in the context of copula based multivariate return periods and using a case study at Durban on the east coast of South Africa. Simulations were used to correlate multivariate return periods of historical events to return periods of estimated storm induced erosion volumes. In addition, the relationship of the most-likely design event (Salvadori et al., 2011) to coastal erosion was investigated. It was found that the multivariate return periods for wave height and duration had the highest correlation to erosion return periods. The most-likely design event was found to be an inadequate design method in its current form. We explore the inclusion of conditions based on the physical realizability of wave events and the use of multivariate linear regression to relate storm parameters to erosion computed from a process based model. Establishing a link between storm statistics and erosion consequences can resolve the ambiguity between multivariate storm return periods and associated erosion return periods.
\end{abstract}

\section{Introduction}

Return periods based on univariate statistical analysis of independent extreme events are widely used to quantify risk in order to specify design conditions in engineering. Typical examples are the estimation of design flood conditions for dam or stormwater designs. In coastal zone management the characterization of storm events that result in beach erosion is an important issue. Univariate return periods are not sufficient for describing a sea storm as it's rarity and destructiveness are a function of wave height $(H)$, wave period $(T)$, storm duration $(D)$, wave direction $(A)$, water level $(W)$ and storm inter-arrival time $(I)$. With respect to coastal erosion the larger the wave height, storm duration and water level the greater the erosion. The contribution of wave period to erosion is less intuitive. van Gent et al. (2008) and van Thiel de Vries et al. (2008) found that an increase in wave period leads to an increase in erosion. However, local fluid particle accelerations decrease with increasing $T$, all else remaining equal, which in turn should provide less erosion potential. The wave direction is not only important from a longshore and cross shore current perspective but also in terms of sheltering. For example, a beach sheltered in a given direction from a 100-yr wave height may experience less erosion than a $50 \mathrm{yr}$ wave height from its exposed direction. The effect of storm inter-arrival time (or it's inverse the storm frequency) is complementary to that of storm duration. If the inter-arrival time between two consecutive storms is short, the beach will not have sufficient time to recover and therefore will be eroding from a lower level. Short interarrival times are therefore in effect similar to an increase in the duration of individual events. 


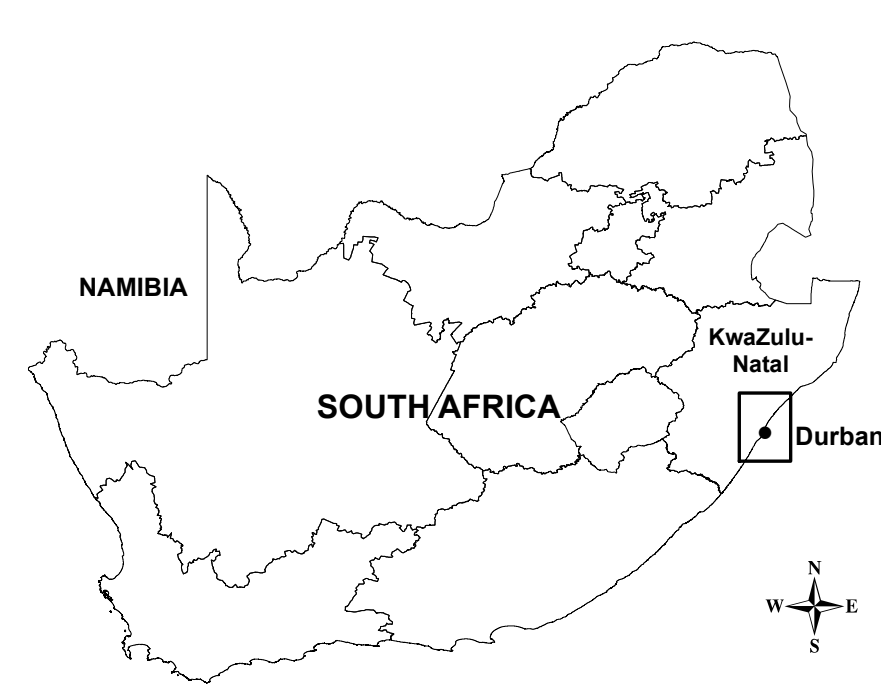

(a)

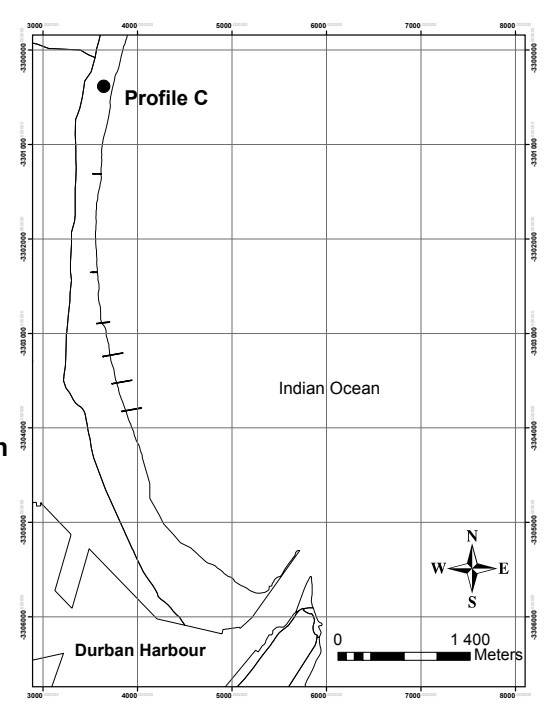

(b)

Fig. 1. A map of (a) South Africa showing Durban and a map of (b) the Durban Bight showing the location of profile C and the Durban harbour.

The synthetic design storm (Carley and Cox, 2003) only considers wave height and duration and it assumes that an $x$-yr storm produces $x$-yr erosion. Considering the interdependence of $H, T, D, A, W$ and $I$ together with their individual and collective influence on erosion, it is overly simplistic to assume that the return period of $H$ and $D$ corresponds to the return period of the corresponding erosion volume. The return periods of design events should therefore be derived from multivariate statistics. In this paper we estimate these multivariate return periods using the approach of copulas and Kendall's return periods as described by Salvadori et al. (2011).

A relationship between sea storm multivariate return periods and erosion return periods could be established from empirical data. However, this is difficult to achieve in practice since beach survey data must be available for both before and after storm events and be close enough to the events that only the effects of the storm are measured. This type of data is often too rare to establish a confident statistical model. In this study we overcome this data shortage by calculating the consequential erosion from historical storm events using the process-based XBEACH model (Roelvink et al., 2009). We then calculate the average recurrence intervals for the simulated erosion volumes and identify which multivariate return periods correspond to the erosion return periods. In essence we attempt to verify the assumptions of the synthetic design storm. We also investigate the selection of a multivariate design event using the Salvadori et al. (2011) most-likely design event method.

\section{Case study}

The east coast of South Africa has 18 yr of reliable wave data from wave recording buoys near the city of Durban (Fig. 1a). Corbella and Stretch (2012a) provide details of the data. Corbella and Stretch (2012b) defined a storm event in terms of a significant wave height threshold as follows: a storm event begins when a significant wave height $H$ exceeds a threshold of $3.5 \mathrm{~m}$ and ends when the significant wave height falls below $3.5 \mathrm{~m}$ for a period of at least 2 weeks. The period between the start and end time, not including the 2 weeks, is the storm duration $D$ and the time between the events is the calm period $I$. The storm definition is illustrated schematically in Fig. 2. The values $H, D, T$ and $W$ are all defined in deep water and experience no sheltering effects.

Durban has an extensive record of beach profiles over 37 yr. Profile C (Fig. 1b) was used exclusively for the present study as it is representative of the Durban Bight, while avoiding most of the sheltering influence of the harbour breakwaters and from the perpendicular beach structures. The records of interest in this study are those that bound storm events and only two events from 1998 and 2007 met these requirements.

\section{Theoretical background and methods}

\subsection{Marginal distributions}

The generalized extreme value (GEV) distribution was used as the marginal distributions of $H, D, T$ and $W$. The GEV has been used extensively for extreme value analysis of hydrological events and specifically for wave heights by Guedes Soares and Scotto (2004); Chini et al. (2010); 


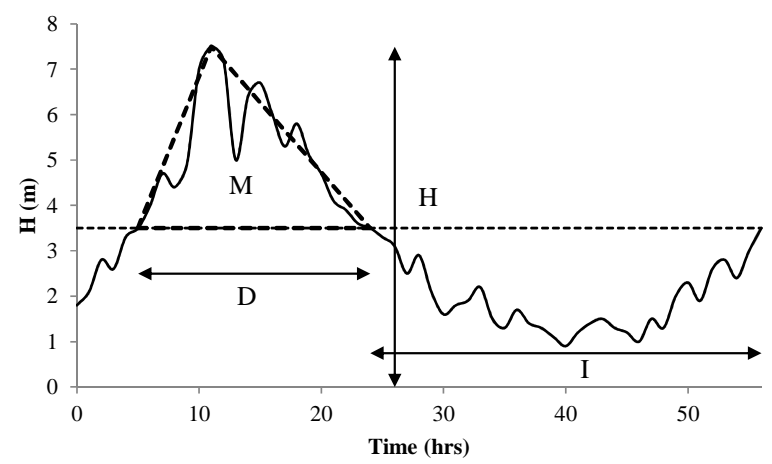

Fig. 2. Illustration of the storm definition showing the significant wave height $H$, storm duration $D$ and calm period $I$.

Mendez (2008); Minguez et al. (2010), and Ruggiero et al. (2010). The GEV encompasses three distributions often referred to as Type I, II and III. The probability density function is given by

$y=\sigma^{-1} \exp \left(-\left(1+k \frac{x-\mu}{\sigma}\right)^{-\frac{1}{k}}\right)\left(1+k \frac{x-\mu}{\sigma}\right)^{-1-\frac{1}{k}}$

for $\left(1+k \frac{x-\mu}{\sigma}\right)<0$ and where $\mu$ is the location parameter, $\sigma$ is the scale parameter and $k$ is the shape parameter.

The maximum likelihood method was used to estimate the GEV parameters and the Akaike information criterion (AIC) was used to evaluate the appropriateness of the GEV model. The AIC is given by

$\mathrm{AIC}=2 n-2 \ln (\mathcal{L})$,

where $n$ is the number of parameters in the probability distribution and $\mathcal{L}$ is the maximized value of the likelihood function for the estimated parameters.

\subsection{Archimedean copulas}

Copulas provide a method of modeling the dependencies between the variables responsible for erosion. They are mathematical functions that join or couple multivariate probability distribution functions to their one-dimensional marginal distribution functions. A detailed introduction to copulas is provided by Nelsen (2006); Salvadori and De Michele (2010); De Michele et al. (2007).

An Archimedean copula $C$ is a solution to the functional equation

$\varphi(C(u, v))=\varphi(u)+\varphi(v)$

where $u=F(x)$ and $v=F(y)$ are marginal distribution functions and $\varphi$ is the generator function.

Corbella and Stretch (2012c) concluded that only $H, T$ and $D$ of the Durban wave data are inter-dependent and they created a fully nested trivariate hierarchical Clayton copula to represent this wave climate. The Corbella and Stretch (2012c) model will be used in this paper. It should be noted that this is typical of a deep ocean coast and shallow seas will have a strong correlation between wave height and water level. The Clayton copula has a generator function expressed as

$\varphi(q)=\frac{1}{\theta}\left(q^{\theta}-1\right)$

where $\theta$ is the dependence parameter and $q$ is a number between 0 and 1 . The 3 -dimensional hierarchical copula has 2 generators, $\varphi_{1}$ and $\varphi_{2}$ and is expressed as

$C\left(u_{1}, u_{2}, u_{3}\right)$

$=\varphi_{2}^{-1}\left(\varphi_{2}\left(\varphi_{1}^{-1}\left[\varphi_{1}\left(u_{1}\right)+\varphi_{1}\left(u_{2}\right)\right]\right)+\varphi_{2}\left(u_{3}\right)\right)$.

The simulations presented in this paper have been performed by the conditional inversion method (Savu and Trede, 2006, 2010; De Michele et al., 2007; Nelsen, 2006). Given the non-exceedance probability of a wave height $h$ the nonexceedance probability of duration $d$ can be estimated from the conditional law $G$ of the bivariate copula as

$G_{2}(d \mid h)=\partial_{h} C(h, d)$.

The non-exceedance probability of the wave period $t$ can then be estimated conditionally based on the given values of $h$ and $d$ from the bivariate and trivariate copula as

$G_{3}(t \mid h, d)=\frac{\partial_{h, d} C(h, d, t)}{\partial_{h, d} C(h, d)}$.

The non-exceedance probability of water level $w$ is assumed independent of $h, d$ and $t$ and is therefore simulated independently.

It should be noted that $H, T$ and $D$ are also dependent on wave direction. Wave direction was precluded from the copula model as all the sampled storm events fall between $110^{\circ}$ and $180^{\circ}$ with an average direction of $147^{\circ}$. Since there is no significant rank correlation between $H$ and wave direction, we assume that all storm events are equally likely to arrive from any direction between $110^{\circ}$ and $180^{\circ}$.

\subsection{Return periods}

A return period or average recurrence interval $\tau$ is the average time (usually expressed in years) between the realizations of two independent successive events. For a given probability level $0<p<1$, the return period can be expressed as (Goda, 2008)

$\tau(p)=\frac{\mu_{T}}{(1-p)}$

where $\mu_{T}$ is the average inter-arrival time of the storms. 


\subsubsection{Multivariate return periods}

An engineer may be concerned with the risks associated with storm events that have various combinations of wave height, storm duration, wave period, etc. With regards to erosion we are interested in the most-likely combination of $H, D, T$ and $W$ for a given probability of exceedance. Unlike dam design where droughts make non-exceedances important, in coastal engineering we are usually only interested in the probability of exceedance. Storm inter-arrival time is an exception, but if parameterized in terms of its inverse, namely as a storm frequency, then the same consideration applies.

The usefulness of multivariate return periods in design work is often debated and the difficulty in their application is associated with linking the statistics to physical consequences. Examples of previous work on multivariate return periods from copulas are Salvadori (2004); Salvadori et al. (2007); Salvadori and De Michele (2010); Salvadori et al. (2011).

A multivariate return period is inherently ambiguous because different combinations of probabilities may produce the same return period. Events that have an equal probability of exceedance define iso-hyper-surfaces or critical layers $L_{q}^{F}$ for a critical level $q$. We adopt the notation from Salvadori et al. (2011) and define a critical layer as

$L_{q}^{F}=\left\{x \in R^{d}: F(x)=q\right\}$

where $F$ is a $d$-dimensional distribution $F=C\left(F_{1}, \ldots, F_{d}\right)$ and $F \in(0,1)$. This definition provides 3 probability regions:

1. a sub-critical region $R_{q}^{<}$that includes events with $F<q$;

2. a critical, set on $L_{q}^{F}$ where all events have a constant $F=q$;

3. a super-critical $R_{q}^{>}$that includes events with $F>q$.

From a coastal engineering perspective we are interested in potentially destructive events, or in other words events in the super-critical region. Salvadori et al. (2011) defines a super-critical return period $\tau_{x}$ for a multivariate random variable $\boldsymbol{X}$ as,

$\tau_{x}=\frac{\mu}{P\left(X \in R_{q}^{>}\right)}$.

Alternatively, $\tau_{x}$ can be defined in terms of the sub-critical region $R_{q}^{<}$as

$\tau_{x}=\frac{\mu}{1-K_{C}(q)}$

where $K_{C}$ is the Kendall's distribution function (Genest et al., 1993) associated with the $d$-copula $C$ and is given by

$K_{C}(q)=P\left(C\left(U_{1}, \ldots, U_{d}\right) \leq q\right)$.

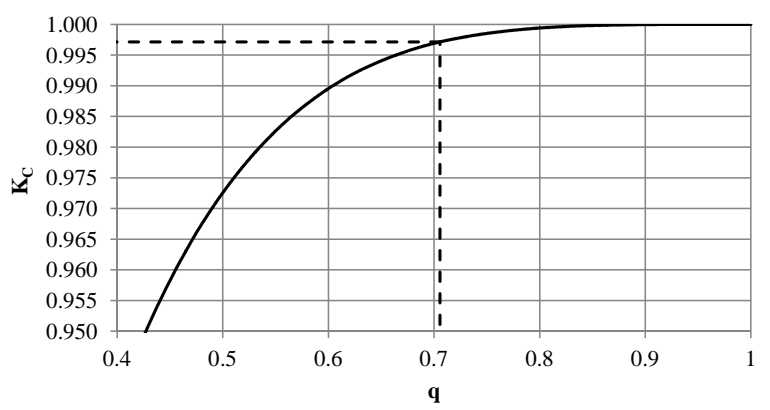

Fig. 3. Simulated relationship between the Kendall's distribution function $K_{C}$ and the critical level $q$ (solid line). The dashed line represents a KRP of $100 \mathrm{yr}$ given by $K_{C}=0.997142$ for a critical level of $q=0.705626$.

Kendall's $K_{C}$ expresses a multivariate quantile relationship (Genest et al., 2001) and measures the probability of events occurring in the region $R_{q}^{<}$, i.e. in the sub-critical region delineated by $L_{q}^{F}$. Since a general analytical expression for $K_{C}$ does not exist for all copula families (Salvadori et al., 2011), we estimate $K_{C}$ from simulations such that for a simulated sample of $m$ variables $\mathbf{u}_{1}, \ldots, \mathbf{u}_{m}$, from a $d$-copula $C$, the estimate of the Kendall's distribution function is

$\hat{K}_{C}(q)=\frac{1}{m} \sum_{i=1}^{m} 1\left(C\left(\mathbf{u}_{i}\right) \leq q\right)$.

\subsection{Kendall's return period}

The return period $\tau_{x}$ in Eq. (11) is referred to as the Kendall's return period (KRP). In order to use the KRP in practice, a relationship between the critical level $q$ and $K_{C}$ is required. Using Eqs. (6) and (7), we simulate 5000000 samples of $h, d, t$ and $w$ in an attempt to produce an almost continuous distribution. The samples were then used to estimate $K_{C}$ for various critical levels $q$. The resulting relationship is shown in Fig. 3 and the dotted line shows the value of $K_{C}$ and $q$ corresponding to a KRP of $100 \mathrm{yr}$. The critical levels corresponding to KRP's of 25, 50 and $100 \mathrm{yr}$ were all calculated and corresponding critical layers inferred for the copula $C(h, d, t, w)$.

\subsection{The most-likely design realization}

Salvadori et al. (2011) presented a solution to the ambiguity problem discussed in Sect. 3.3.1 by proposing the mostlikely design event method. The method essentially uses the density of the multivariate distribution to identify which values lying on $L_{q}^{F}$ are relatively more likely to occur than others. The most-likely design realization $\delta_{\mathrm{ML}}$ for a critical level $q$ was defined as

$\delta_{\mathrm{ML}}=\underset{\boldsymbol{x} \in L_{q}^{F}}{\arg \max _{F}} f(\boldsymbol{x})$ 
where $f(\boldsymbol{x})$ is the multivariate density and for our model is given by

$$
\begin{aligned}
f(\boldsymbol{x}) & =f(H, T, D, W) \\
& =c(F(H), F(T), F(D)) \\
& f(H) . f(T), f(D), f(W)
\end{aligned}
$$

and where $c(\cdot)$ is the trivariate copula density given by

$c(h, d, t)=\frac{\partial^{3}}{\partial_{h} \partial_{t} \partial_{d}} C(h, t, d)$.

The most-likely design realization unfortunately does not have any direct link to physical processes and so cannot in general provide a design storm event that is meaningful in terms of its physical consequences. This can only be achieved by linking storm characteristics to erosion, which is considered in Sect. 4.3.

\subsection{Erosion estimation by process-based models}

There are numerous process-based numerical models available for estimating cross-shore erosion (Schoonees and Theron, 1995). Corbella and Stretch (2012d) compared XBEACH to SBEACH (Larson et al., 1990) and the Time Convolution model (Kriebel and Dean, 1993). They concluded that XBEACH provided the best results for the Durban beaches and it was therefore adopted for the present study. XBEACH is a public-domain model and although it is not yet fully developed, it has been used in numerous recent studies that have shown it's results to be satisfactory (e.g. Roelvink et al., 2009; Hartanto et al., 2011).

The copula model was constructed from wave data recorded in a water depth of approximately $40 \mathrm{~m}$. Simulated waves therefore need to be transformed into nearshore conditions. The SWAN model was used to transform the wave conditions to a $20 \mathrm{~m}$ depth at the seaward boundary of the XBEACH model domain.

\section{Results}

\subsection{Empirical erosion}

The empirical erosion data was limited to storms that occurred in the years 1998 and 2007. The 1998 storm event caused profile $\mathrm{C}$ (refer Fig. 1) to erode $133 \mathrm{~m}^{3} \mathrm{~m}^{-1}$ and the 2007 storm event caused the profile to erode $137 \mathrm{~m}^{3} \mathrm{~m}^{-1}$. Using the relationship developed between KRP and the critical level $q$ in Sect. 3.3.1, the return periods for the 2007 and 1998 storms were estimated as $120 \mathrm{yr}$ and $15 \mathrm{yr}$, respectively.

Although there is a large difference in the storm return periods, the resulting erosion was almost identical. This demonstrates the difficulties associated with multivariate return periods. The relationship between storm return periods and erosion return periods is non-linear and different profiles can behave differently.

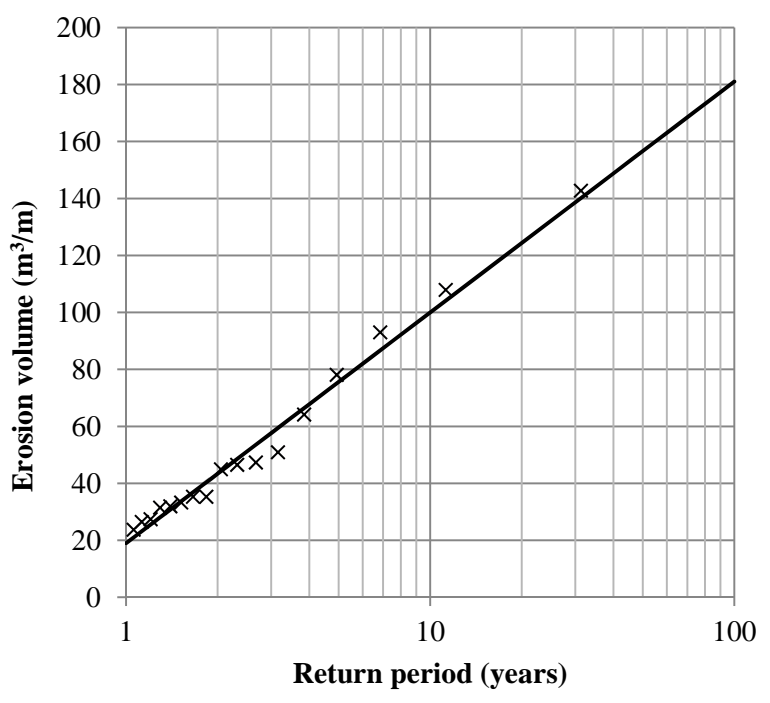

Fig. 4. The return periods of $\mathrm{XBEACH}$ simulated erosion volumes for profile $\mathrm{C}$ with the fitted exponential distribution (solid line).

\subsection{Erosion return periods}

In order to calculate erosion volumes a beach profile measurement is required before and after a storm. Since such data was only available on two occasions we estimate the erosion of past events using XBEACH. The historical storm events were first idealized using the definition in Fig. 2 and then used to quantify the erosion at profile $\mathrm{C}$. The limitations of these simulations are the idealization of the wave height, the constant wave direction of $147^{\circ}$ (refer to Sect. 3.2) and the identical pre-storm beach profile shape. Figure 4 shows the calculated erosion volumes $\left(\mathrm{m}^{3} \mathrm{~m}^{-1}\right)$ for recurrence intervals up to $100 \mathrm{yr}$ with a fitted exponential distribution. These erosion return periods represent a volume lost from the average volume of profile $\mathrm{C}$ and do not consider storm inter-arrival time $^{1}$. If a designer is concerned with the effects of interarrival times we suggest that it can be included by increasing the storm duration or alternatively modeling the calm period using a non-stationary Poisson process.

In an attempt to identify which return periods best represent erosion return periods we calculate Kendall's tau rank correlation coefficients between the erosion return periods and univariate storm return periods $\tau(H), \tau(D), \tau(T), \tau(W)$, and multivariate storm return periods, $\tau(H D), \tau(H D T)$ and $\tau(H D T W)$. The results are shown in Table 1. Storm duration $D$ had the strongest correlation with erosion, followed by wave height $H$. Wave period $T$ has a moderate correlation and water level $W$ has no significant correlation. The Kendall's return period $\tau(H D T W)$ has a weaker correlation than $\tau(H)$ mainly because it includes the water level that has no correlation. The multivariate return period correlations

\footnotetext{
${ }^{1}$ Note that the volumes are calculated above $1 \mathrm{~m}$ Chart Datum while mean sea level is about $1.1 \mathrm{~m}$ Chart Datum at this location.
} 
Table 1. Kendall's tau correlation coefficients between the simulated erosion return periods and the various multivariate storm return periods. The statistical significance of the correlations are indicated by their corresponding p-values.

\begin{tabular}{lll}
\hline Erosion vs & Correlation coefficient & $\mathrm{p}$-value \\
\hline$\tau(D)$ & 0.78 & $6.77 \times 10^{-17}$ \\
$\tau(H)$ & 0.56 & $2.88 \times 10^{-09}$ \\
$\tau(T)$ & 0.30 & $1.49 \times 10^{-03}$ \\
$\tau(W)$ & 0.03 & $7.50 \times 10^{-01}$ \\
\hline$\tau(H D)$ & 0.76 & $4.47 \times 10^{-16}$ \\
$\tau(H D T)$ & 0.63 & $1.94 \times 10^{-11}$ \\
$\tau(H D T W)$ & 0.50 & $9.21 \times 10^{-08}$ \\
\hline
\end{tabular}

improve with fewer variables - the correlation with $\tau(H D T)$ improves on $\tau(H D T W)$, and $\tau(H D)$ gives a further improvement. Note that all these correlation results may be expected to depend on the definition used for the storm events (Fig. 2).

The correlations provide insight into an appropriate multivariate description of an erosion event but do not undisputedly determine the combination of $H$ and $D$ as the best multivariate descriptor. To illustrate this we consider the 2007 event. The 2007 event was the largest event ever recorded in Durban. The Kendall's return periods $\tau(H D T W)$ and $\tau(H D)$ of the 2007 event were $120 \mathrm{yr}$ and $57 \mathrm{yr}$, respectively. Return periods $\tau(H D T)$ and $\tau(H)$ were $34 \mathrm{yr}$ and $31 \mathrm{yr}$, respectively. The return period of the erosion predicted by XBEACH for the idealized storm event was $34 \mathrm{yr}$. This demonstrates that in this case $\tau(H D T)$ or $\tau(H)$ provide the best descriptions of the probability of the erosion event. In fact, considering the 5 largest erosion volumes, the erosion return periods may be described best by either the return periods $\tau(H), \tau(D), \tau(T)$, $\tau(W)$ or $\tau(H D T)$ depending on which parameter dominates the erosion process. Generally $\tau(H D)$ provides a reasonable estimate of the erosion return period.

Ideally, the erosion return period would be identical to the storm return period. The following section is an attempt to provide a method to estimate events with improved correspondence.

\subsection{Selecting design storms}

The most-likely design realization is a purely statistical definition. It could be a rare event that does not cause significant erosion of the coastline. For example it may select the storm with the smallest significant wave height and water level, but with an extremely improbable duration. That combination of parameters may result in a long return period but in reality the duration of such an event may be infinitely long without causing any erosion, i.e. erosion may be insensitive to duration for that parameter range.

Table 2 shows the results of the most-likely design estimate. Significant wave heights between $4 \mathrm{~m}$ and $5 \mathrm{~m}$ were
Table 2. The most-likely design realizations for multivariate return periods 25,50 and $100 \mathrm{yr}$ and the associated erosion return periods.

\begin{tabular}{lccc}
\hline Storm return period $(\mathrm{yr})$ & 25 & 50 & 100 \\
\hline Storm characteristics: & & & \\
$H(\mathrm{~m})$ & 4.51 & 4.67 & 4.87 \\
$T(\mathrm{~s})$ & 16.0 & 16.7 & 16.7 \\
$D(\mathrm{~h})$ & 29.9 & 39.9 & 51.4 \\
$W(\mathrm{~m})$ & 1.00 & 1.01 & 1.03 \\
\hline Erosion volume $\left(\mathrm{m}^{3} \mathrm{~m}^{-1}\right)$ & 50 & 70 & 93 \\
Erosion return period $(\mathrm{yr})$ & 3 & 4 & 8 \\
\hline
\end{tabular}

estimated for the return periods of 25,50 and $100 \mathrm{yr}$. The actual observed values ranged between $3.5 \mathrm{~m}$ and $8.5 \mathrm{~m}$ which places the most-likely design events at the lower end of the observed range. The most-likely design method selects events that we can expect to see more often. However there is an immediate problem evident - all the event parameters share an equal weighting statistically but not in terms of their physically influence on erosion. Given that wave height is a principal parameter in erosion it should have greater importance. The result is that the 25,50 and $100 \mathrm{yr}$ storm return periods correspond to erosion return periods of 3,4 and $8 \mathrm{yr}$, respectively (Table 2 ). The risks associated with the recurrence of the storm events are not consistent with those associated with their consequential erosion levels.

The following sections consider ways of constraining or refining the selection of the most-likely design realization by including the physical relationships between $H, T, D$ and $W$, and the sensitivity of the erosion consequences to each.

\subsubsection{Constraints due to wave mechanics}

The statistical model has no accommodation for the mechanics of water waves, namely the processes in the generation and propagation of ocean waves. Purely statistical models may need to be constrained to avoid unrealistic results. For example there is a physical limitation on wave steepness before they break and dissipate. Wave steepness is defined as the wave height $(H)$ divided by the wave length $(L)$ and for deep water waves is given by (e.g. Goda, 2008)

$\frac{H}{L}=\frac{2 \pi H}{g T^{2}}$.

The maximum wave steepness is usually assumed to be $\frac{1}{7}$ (Michell, 1893). It should be noted that the $\frac{1}{7}$-th relationship is for regular waves and has limited value when applied to random wave conditions.

Physical constraints on wave heights and/or periods may also be associated with the wave generation processes and their distance from the area of interest. Storm durations may have realizability constraints related to atmospheric 
circulation patterns or other factors. All these additional constraints are highly location specific.

Applying the wave steepness constraint alone to the selection of the most probable design event does not change the results shown in Table 2 for the case study site.

\subsubsection{Linking erosion to storm characteristics}

The next issue is to link the storm characteristics directly to their erosion consequences. As already noted in Sect. 4.1, direct measurements of the erosion due to specific storm events are rare and difficult to obtain. A method of overcoming this limitation is to use a process-based model, such as XBEACH, to quantify the erosion due to each storm event. Since the model attempts to represent the dominant physical processes that drive erosion, this approach should reflect the underlying physics of the problem. However, identical antecedent conditions are assumed for each profile response simulation which does not reflect the actual situation for all events. Furthermore, it is currently not practical to use this approach to accurately map the erosion caused by a comprehensive range of all possible storm parameters. Instead we use the simulation results previously employed for the analysis of the erosion return periods (Fig. 4) and extrapolate from this sample by relating the erosion magnitudes to the storm parameters $H$, $T, D$ and $W$ using multiple linear regression. The regression equation was chosen to have the form of a truncated Taylor series expansion, namely

$$
\begin{aligned}
E=E_{0} & +E_{H} H+E_{D} D+E_{T} T+E_{W} W \\
& +E_{H H} H^{2}+E_{H D} H D+E_{H T} H T+E_{H W} H W \\
& +E_{D D} D^{2}+E_{D T} D T+E_{D W} D W \\
& +E_{T T} T^{2}+E_{T W} T W \\
& +E_{W W} W^{2} \\
& +\epsilon
\end{aligned}
$$

where the coefficients $E_{0}, E_{H}, \ldots$ are chosen to minimize the sum of the squared errors $\epsilon$. The results are plotted in Fig. 5 and indicate that the regression model is adequate in this case. Higher order terms could be included in Eq. (19) to improve the results if necessary. The important outcome of this analysis is that Eq. (19) allows iso-surfaces of erosion (and their associated return periods) to be located in the $H, T, D, W$ parameters space. For example Fig. 6 shows a surface plot of erosion, together with iso-erosion contours, for a constant wave period, $T=16 \mathrm{~s}$, and water level $W=$ $1.0 \mathrm{~m}$ above mean sea level. In this way individual storms can be related directly to their erosion consequences. For example to estimate a storm event $(H T D W)$ representative of a 100 year erosion level $\left(180 \mathrm{~m}^{3} \mathrm{~m}^{-1}\right)$ we use the regression model to determine the $H, T, D$, and $W$ combinations that produce the erosion within a specified tolerance. We then use the most-likely design event to choose the most probable events associated with the desired erosion level. The method is il-
Table 3. The storm parameters associated with the multivariate return periods 25,50 and $100 \mathrm{yr}$ and the associated erosion return periods calculated by incorporating a multiple linear regression with the most-likely design event.

\begin{tabular}{lccc}
\hline Storm return period $(\mathrm{yr})$ & 25 & 50 & 100 \\
\hline Storm characteristics: & & & \\
$H(\mathrm{~m})$ & 4.63 & 5.00 & 10.3 \\
$T(\mathrm{~s})$ & 16.9 & 17.5 & 17.4 \\
$D(\mathrm{~h})$ & 90.4 & 95.0 & 83.9 \\
$W(\mathrm{~m})$ & 0.85 & 0.86 & 0.87 \\
\hline Erosion volumes $\left(\mathrm{m}^{3} \mathrm{~m}^{-1}\right)$ & 132 & 160 & 193 \\
Erosion return periods $(\mathrm{yr})$ & 25 & 56 & 141 \\
\hline
\end{tabular}

lustrated in Fig. 7 that shows level curves for storms (solid lines) and erosion (dashed lines) for return periods of 100 , 50 and $25 \mathrm{yr}$ and for constant $T=15 \mathrm{~s}$ and $W=1 \mathrm{~m}$ above mean sea level. The intersection of storm lines with the erosion lines represents a point where the erosion return period is equal to the storm return period. In four dimensions this intersection is not unique and so the most-likely design event is used to select the most probable event. This method was performed for 25,50 and $100 \mathrm{yr}$ erosion return periods. The resulting storms (combinations of $H, T, D, W$ ) were then run through XBEACH to verify the method. Table 3 shows that the method produces erosion return periods that are consistent with the storm return periods. The $25 \mathrm{yr}$ return periods correspond exactly and there is only a minor difference between the $50 \mathrm{yr}$ events. The $100 \mathrm{yr}$ storm event translates to an erosion of $141 \mathrm{yr}$. Although this difference seems significant, when comparing the erosion volumes there is less than $10 \%$ difference between the $100 \mathrm{yr}\left(180 \mathrm{~m}^{3}\right)$ and $141 \mathrm{yr}$ $\left(193 \mathrm{~m}^{3}\right)$ erosion event. The difference can be attributed to errors and/or uncertainties in the regression model and the erosion probability distribution for extreme events.

\section{Discussion}

In an ideal situation a multivariate return period of a storm would be equivalent to that of the erosion associated with that storm. This would provide a quantifiable risk to the multivariate return period and make the design process simpler.

The most-likely design event has been suggested as a method for identifying design events, but without a direct link to its physical consequences (in this case erosion) it cannot provide a meaningful measure of the associated risks. A link can be provided by using a "structure function" approach (e.g. Hawkes, 2008 and Callaghan et al., 2008). The complexity in achieving this can be appreciated by considering the effects of storm duration. Equilibrium profile theory suggests that an increased water level and wave height will cause a beach profile to retreat to a new equilibrium level. For this new equilibrium to be established the sea conditions 


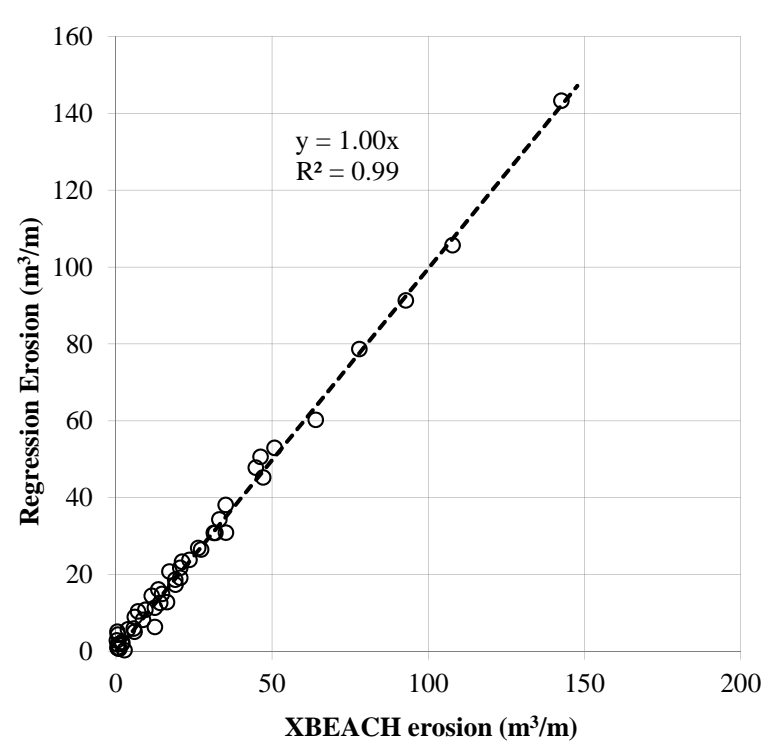

Fig. 5. A comparison of the erosion estimated from the multiple linear regression and $\mathrm{XBEACH}$.

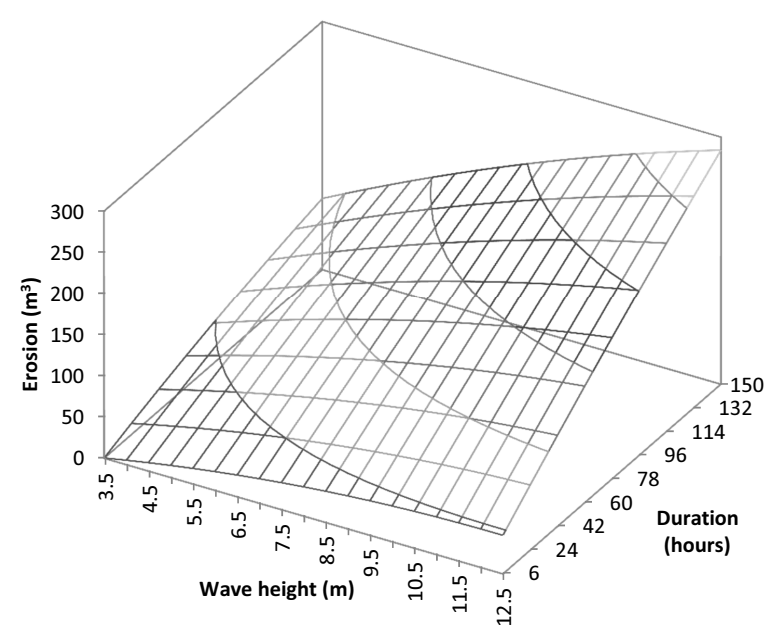

Fig. 6. Surface plot of erosion as a function of wave height $H$ and storm durations $D$, for the given wave period $T=16 \mathrm{~s}$ and water level $W=1.0 \mathrm{~m}$ above mean sea level. Contours of erosion levels $50,100,150,200,250 \mathrm{~m}^{3} \mathrm{~m}^{-1}$ are shown on the surface. Corresponding erosion return periods can be inferred from Fig. 4.

must be sustained for a certain amount of time. Once this threshold of time has been exceeded the profile will cease to change further. This means that a statistical model may predict a rare storm duration of say $300 \mathrm{~h}$ but it will not cause any more erosion than a 100 -h storm. That is, the sensitivity of erosion to the storm duration may decrease as the duration increases. Therefore, beyond a certain duration threshold it may be more appropriate to consider the occurrence of larger wave heights instead of longer durations.

The ambiguity of multivariate return periods has not been sufficiently developed for practicing designers to employ

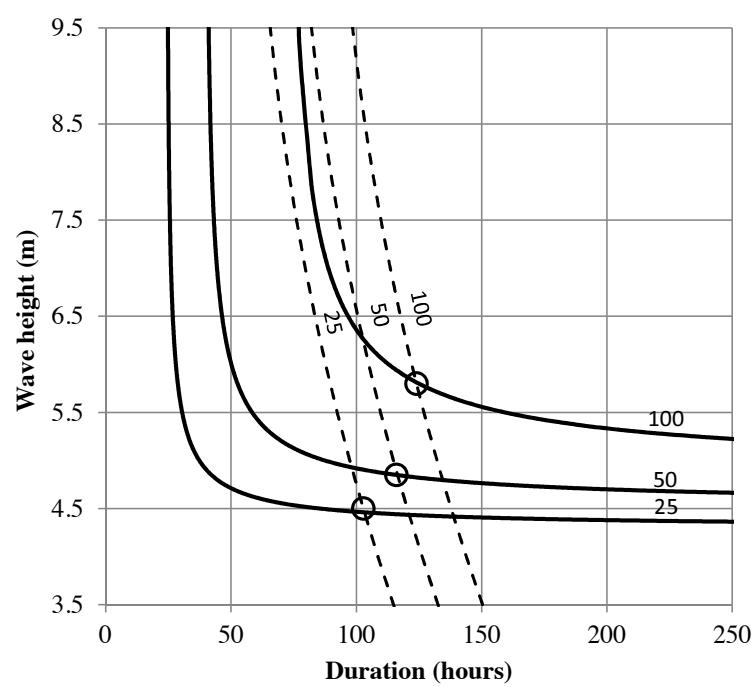

Fig. 7. Level curves of storm parameters $H$ and $D$ for storm (solid lines) and erosion (dashed lines) return periods of 100,50 and $25 \mathrm{yr}$ for $T=15 \mathrm{~s}$ and $W=1.0 \mathrm{~m}$ above mean sea level

them in coastal applications. We have proposed a method that can estimate storm events that are analogous to that of associated erosion events. The multivariate analysis is fairly complicated to implement and although it is the correct way to define a storm return period, we suggest a univariate analysis of $H$ and $D$ and a bivariate analysis of $H D$ may provide a reasonable engineering estimate of the associated erosion return period. We suggest that if the wave height return period is significantly larger than that of the duration then the erosion return period will approximate the wave height return period and vice versa. If the wave height and duration return periods are similar then the bivariate return period may be representative of the erosion and thus satisfy the assumptions of the synthetic design storm (Carley and Cox, 2003).

Typically, a univariate analysis of storm parameters inadequately describes the erosion potential of a multivariate storm event. Table 4 shows the various return period definitions for the events presented in Table 3. None of the return periods except the trivariate $\tau(H D T)$ are close to being consistent with the corresponding erosion return periods. In this case the lower dimensional return periods overestimate the risk (or underestimate the return periods) associated with the storm erosion.

The use of return periods that are directly linked to erosion consequences is important for well-informed coastal management. Coastal managers often make decisions on wave parameter based return periods without understanding that the associated impact may be significantly different. The method demonstrated in this paper allows the estimation of an unambiguous return period from limited field data by simulating sea storm erosion in XBEACH. Combined with multivariate regression, this essentially yields a structure function in the spirit of those described by Coles and Tawn (1994) 
Table 4. The magnitude of different return periods (univariate, bivariate, etc.) for the events listed in Table 3 which were selected to have multivariate return periods of 25,50 and $100 \mathrm{yr}$ with matching associated erosion return periods.

\begin{tabular}{lccc}
\hline Storm return period $(\mathrm{yr})$ & 25 & 50 & 100 \\
\hline Return period definition $(y r):$ & & & \\
$\tau(H)$ & 2.0 & 3.1 & 58 \\
$\tau(T)$ & 7.3 & 13 & 11 \\
$\tau(D)$ & 3.2 & 3.3 & 3.0 \\
$\tau(W)$ & 1.6 & 1.7 & 1.8 \\
$\tau(H D)$ & 4.0 & 6.3 & 14 \\
$\tau(H D T)$ & 16 & 37 & 100 \\
\hline
\end{tabular}

and Reeve (1998). The regression derived structure function is expected to be site and project specific and would have to be re-computed using XBEACH (or from a detailed record of beach surveys) for each application.

\section{Conclusions}

This paper has explored the relationship between multivariate return periods and erosion return periods through a simulation study. Kendall's return period provides a promising description of copula based return periods. Durban's largest storm event on record, the 2007 storm, was estimated to have a $120 \mathrm{yr}$ (multivariate) return period with a $34 \mathrm{yr}$ erosion return period. Based on simulations of idealized historical storms, the multivariate return period with the strongest correlation to erosion return period was a bivariate return period of wave height and duration. We have shown that a univariate analysis of storm parameters cannot adequately describe erosion risks and will lead to overestimation. Caution is required when attempting to define erosion risks by simple return periods of few dimensions. The most-likely design event proposed by Salvadori et al. (2011) provides a means to overcome the ambiguity of multivariate return periods by selecting the most probable events for a specified exceedance probability. However, the method is purely statistical and the lack of any link to the underlying physical consequences limits its usefulness for design applications. We have created a type of erosion structure function using multiple linear regression and based on the XBEACH model. This erosion structure function has been used to improve the appropriateness of the design event estimates. The results suggest that appropriate conditioning can provide a method for estimating multivariate storm return periods that are consistent with the return periods of their consequential erosion events. Further research is required to investigate the generality of this approach and should involve testing at other locations with different wave climates and shoreline characteristics.
Acknowledgements. We thank the eThekwini Municipality for the use of beach profile data and Transnet Port Authority for access to wave data. We also thank Profs Geoff Pegram and Andras Bardossy for their comments on a draft of the paper, and the reviewers for their constructive feedback.

Edited by: O. Katz

Reviewed by: P. Hawkes and one anonymous referee

\section{References}

Callaghan, D. P., Nielsen, P., Short, A., and Ranasinghe, R.: Statistical simulation of wave climate and extreme beach erosion, Coast. Eng., 55, 375-390, 2008.

Carley, J. T. and Cox, R. J.: A methodology for utilising timedependent beach erosion models for design events, Proceedings of the 16th Australasian Coastal \& Ocean Engineering Conference, Auckland, New Zealand, 2003.

Coles, S. G. and Tawn, J. A.: Statistical Methods for Multivariate Extremes: an Application to Structural Design, Appl. Statist., 43, $1-48,1994$.

Corbella, S. and Stretch, D. D.: The wave climate on the KwaZuluNatal coast, South Africa., J. S. Afr. Inst. Civ. Eng., 54(2), in press, 2012a.

Corbella, S. and Stretch, D. D.: Shoreline recovery from storms on the east coast of Southern Africa, Nat. Hazards Earth Syst. Sci., 12, 11-22, doi:10.5194/nhess-12-11-2012, $2012 b$.

Corbella, S. and Stretch, D. D.: Simulating a multivariate sea storm using Archimedean Copulas, Coast. Eng., submitted, 2012c.

Corbella, S. and Stretch, D. D.: Predicting coastal erosion trends using non-stationary statistics and process-based models. Coast. Eng., 70, 40-49, 2012d.

Chini, N., Stansby, P., Leake, J., Wolf, J., Roberts-Jones, J., and Lowe, J.: The impact of sea level rise and climate change on inshore wave climate: A case study for East Anglia (UK), Coast. Eng., 57, 973-984, 2010.

De Michele, C., Salvadori, G., Passoni, G., and Vezzoli, R.: A multivariate model of sea storms using copulas, Coast. Eng, 54, 734751, 2007.

Genest, C. and Rivest, L.-P.: Statistical inference procedures for bivariate Archimedean copulas, J. Am. Stat. Assoc., 88, 10341043, 1993.

Genest, C. and Rivest, L.-P.: On the multivariate probability integral transformation, Stat. Probab. Lett., 53, 391-399, 2001.

Goda, Y.: Random Seas and Design of Maritime Structures, 2nd Edn., World Scientific Publishing Co. Pte. Ltd. Singapore, 2008.

Guedes Soares, C. and Scotto, M. G.: Application of the r largestorder statistics for long-term predictions of significant wave height, Coast. Eng., 51, 387-394, 2004.

Hartanto, I. M., Beevers, L., Popescu, I., and Wright, N. G.: Application of a coastal modelling code in fluvial environments, Environ. Model. Softw., 26, 1-11, 2011.

Hawkes, P. J.: Joint probability analysis for estimation of extremes, J. Hydraul. Res., 46, 246-256, 2008.

Kriebel, D. L. and Dean, R. G.: Convolution method for timedependent beach-profile response, J. Waterw. Port C., 119, 204 226, 1993.

Larson, M., Kraus, N. C., and Byrnes, M. R.: SBEACH: Numerical model for simulating storm-induced beach change, Report 2, 
Numerical formulation and model tests, Technical report CERC89-9, US Army Engineer Waterways Experiment Station, Vicksburg, MS, 1990.

Mendez, F. J., Menendez, M., Luceno, A., Medina, R., and Graham, N. E.: Seasonality and duration in extreme value distributions of significant wave height, Ocean Eng., 35, 131-138, 2008.

Michell, J. H.: On the Highest Wave in Water, Phil. Mag., 36, 430435, 1893.

Minguez, R., Menendez, M., Mendez, F. J., and Losada, I. J.: Sensitivity analysis of time-dependent generalized extreme value models for ocean climate variables, Adv. Water Resour., 33, 833-845, 2010.

Nelsen, R. B.: An introduction to copulas, 2nd Edn., Springer Series in Statistics, Springer, New York, 2006.

Reeve, D. E.: Coastal Flood Risk Assessment, J. Waterway Port C., 124, 219-228, 1998.

Roelvink, D., Reniers, A., van Dongeren, A., van Thiel de Vries, J., McCall, R., and Lescinski, J.: Modelling storm impacts on beaches, dunes and barrier islands, Coast. Eng., 56, 1133-1152, 2009.

Ruggiero, P., Komar, P. D., and Allan, J. C.: Increasing wave heights and extreme value projections: The wave climate of the US Pacific Northwest, Coast. Eng., 57, 539-552, 2010.

Salvadori, G.: Bivariate return periods via 2-Copulas, Stat. Methodol., 1, 129-144, 2004.

Salvadori, G. and De Michele, C.: Multivariate multiparameter extreme value models and return periods: A copula approach, Water Resour. Res., 46, W10501, doi:10.1029/2009WR009040, 2010.
Salvadori, G., De Michele, C., Kottegoda, N. T., and Rosso, R.: Extremes in Nature, An Approach Using Copulas, Water Science and Technology Library, Springer, 56, ISBN 978-1-4020-44144, 292 pp., 2007.

Salvadori, G., De Michele, C., and Durante, F.: On the return period and design in a multivariate framework, Hydrol. Earth Syst. Sci., 15, 3293-3305, doi:10.5194/hess-15-3293-2011, 2011.

Savu, C. and Trede, M.: Hierarchical Archimedean copulas, available at: http://www.uni-konstanz.de/micfinma/conference/Files/ $\sim$ papers/ (last access: 1 November 2011), 2006.

Savu, C. and Trede, M.: Hierarchies of Archimedean copulas, Quant. Financ., 10, 295-304, 2010.

Schoonees, J. S. and Theron, A. K.: Evaluation of 10 cross-shore sediment transport/morphological models, Coast. Eng., 25, 1-41, 1995.

Sklar, A.: Fonctions de repartition a n dimensions et leurs marges, Publications de l'Institut de Statistique de l'Université de Paris, 8, 229-231, 1959.

van Gent, M. R. A., van Thiel de Vries, J. S. M., Coeveld, E. M., de Vroeg, J. H., and van de Graaff, J.: Large-scale dune erosion tests to study the influence of wave periods, Coast. Eng., 55, 1041$1051,2008$.

van Thiel de Vries, J. S. M., van Gent, M. R. A., Walstra, D. J. R., andReniers, A. J. H. M.: Analysis of dune erosion processes in large-scale flume experiments, Coast. Eng., 55, 1028-1040, 2008. 